\title{
Correlation of Ankle-Brachial Index and Ultrasound Findings on Dorsalis Pedis Artery and Posterior Tibial Artery in Patients with Diabetic Foot Ulcer Dedy Pratama ${ }^{a *}$, Mulawardi Mulawardi ${ }^{b}$, Patrianef Darwis ${ }^{a}$
}

Introduction: In patients with diabetic foot ulcers, atherosclerosis, and endothelial dysfunction can worsen the patient's vascular condition. Atherosclerosis is one of which is assessed by the ankle-brachial index ( $\mathrm{ABI})$. The occurrence of endothelial dysfunction can be identified indirectly from the examination of flow-mediated dilatation (FMD) via doppler ultrasound. This study was conducted to determine whether there is a correlation between the ankle-brachial index examination with ultrasound examinations of the dorsalis pedis artery and posterior tibial arteries in diabetic foot sufferers.

Method: The study design was a cross-sectional prospective conducted on $11^{\text {th }}$ November $15^{\text {th }}$ December 2014 at Cipto Mangungkusumo National Hospital, Fatmawati National Hospital, and Tangerang Hospital. The inclusion criteria used were diabetics and allow for $\mathrm{ABI}$ examination and ultrasonography. Patients who did not have a precise diagnosis and had undergone a major amputation of the leg examined were excluded from the study.

Results: From the Spearman non-parametric correlation analysis test results obtained significant results on the correlation between $A B I$ and posterior tibial artery volume flow (VF) $(p=0.021)$. In contrast, insignificant results were obtained on the correlation between peak systolic velocity (PSV) dorsalis pedis artery with $A B I(p=0.561)$, as well as an insignificant correlation between VF of dorsalis pedis artery with $A B I(p=0.143)$, as well as insignificant correlation on PSV of posterior tibial artery with $A B I(p=0.231)$ The results of Spearman's non-parametric correlation analysis test results obtained significant results on the correlation between $A B I$ and $A B I$ spectral picture $(p=0,000)$ in the diabetic foot.

Conclusion: There was a significant correlation between the posterior tibial artery VF with $A B I$ and the Doppler ultrasound spectral picture with $A B I$.

Keywords: ultrasound doppler, ankle-brachial index, diabetic foot ulcer, dorsalis pedis artery, popliteal artery

https://doi.org/10.36864/jinasvs.2020.2.002

*Correspondence: dedygpratama@yahoo.com

a.D., Vascular and Endovascular Division, Department of Surgery, Cipto Mangunkusumo Hospital - Faculty of Medicine, Universitas Indonesia, Jakarta, Indonesia

bM.D., Department of Surgery, Dr. Wahidin Sudirohusodo, South Sulawesi, Indonesia

\section{INTRODUCTION}

Based on WHO data from The International Working Group in the Diabetic Foot, "diabetic foot" is defined as a diabetic foot sufferer with ulceration, infection, and destruction of the inner tissue due to neurological abnormalities accompanied by varying degrees of peripheral vascular abnormalities in the lower limbs. ${ }^{1}$ Around the world, at least $5 \%$ of diabetics have a history of foot ulcers, and about $15 \%$ of patients have a risk of developing ulcers during their life. ${ }^{1-2}$ The prevalence of foot ulcers in patients with diabetes in developing countries reaches 4$10 \% .^{3}$

Vascular disorders in people with diabetes are almost entirely caused by atherosclerosis, where the same conditions are also found in people with hypertension and non-diabetics smokers, only in people with diabetes. This disorder is obtained at a younger age. Plaque that occurs in atherosclerosis causes unevenness of the inner surface of the arteries, and turbulence of blood flow that occurs facilitates thrombosis. If the entire artery lumen is blocked, and if there is insufficient collateral flow, severe ischemia will occur. ${ }^{4}$

The mildest complaints that occur in a state of mild ischemia (narrowing) or vascular insufficiency is intermittent claudication. Patients feel complaints such as convulsions and discomfort around the thigh or pelvis, which gradually disappear after a few minutes of rest, but complaints will reappear when walking. Pain may be replaced by a feeling of loss of limbs (giving out). Complaints in claudication will decrease and disappear by avoiding risk factors such as smoking, hypertension, hypercholesterolemia, obesity, and hyperglycemia. ${ }^{5}$ 
Heavier complaints appear in the form of pain at rest or pain at night. Pain during rest is felt like a burning sensation in the area of the leg's tip, which usually persists. Pain at night is related to the legs' position and will improve if the legs are hung on the edge of the bed or stroll. This situation is a sign that there is a threat to the legs, which are often not felt by people with diabetic foot due to peripheral neuropathy. ${ }^{5}$ Therefore, for every diabetic ulcer patients, it is essential always to assess the condition and peripheral vascular status.

There are various macrocirculation examination methods to identify non-viable limbs or non-healing lesions, which are most often caused by atherosclerosis. Peripheral vascular examination through comparison of systolic pressure in the ankle and brachial, known as the ankle-brachial index (ABI) or ankle-brachial pressure index (ABPI), has long been an option. In this examination, a comparison of inferior and superior extremity blood pressure is performed. The normal state is obtained if the $A B I$ value is around $1, A B I$ value $<0.9$ indicates an occlusion in the arteries, and an ABI value of 0.50 0.80 is considered to have a single occlusion in the arterial system. ABI values $<0.50$ indicate multiple occlusions in the leg arteries. The specificity of this examination approached $100 \%$, while the sensitivity ranged from $92-95 \% 11$. Patrianef's study found that the average $A B I$ value of a diabetic ulcer when first examined was $0.898 .^{6}$ This showed that the majority of patients had suffered from vascular disorders in the form of the leg arteries occlusion.

Endothelial lining in all blood vessels is no longer considered a passive structure, but has been known to play an essential role in the regulation of vasomotor tone, the process of thrombogenesis, inflammation, and vascular smooth growth muscle cells. The occurrence of endothelial dysfunction can be identified indirectly from the examination of flowmediated dilatation (FMD) via doppler ultrasound. This mechanism is based on the shear generated by the blood vessels flow when the blood vessels are dilated. The shear load will induce the release of ATP or substance $P$ from endothelial cells to produce NO. In addition to inducing ATP release, the increased flow will also deliver more ATP to the surface of endothelial cells, so that more ATP reaches the receptor to stimulate synthesis and release of NO from the endothelium. This condition is called the FMD effect on the endothelium. In healthy endothelial arteries, an increase in blood flow will cause a vasodilation effect, but this mechanism does not occur in endothelial dysfunction. Therefore, in arteries that have undergone atherosclerosis, and arteries that are exposed to risk factors for atherosclerosis but have not shown signs of atherosclerosis, FMD disturbances can occur. ${ }^{7-8}$

This study was conducted to determine whether there is a correlation between the results of the ankle-brachial index examination with ultrasound examination of the dorsalis pedis artery and posterior tibial arteries in diabetic foot sufferers. Doppler ultrasound examination includes arterial diameter, pattern, and speed of blood flow (volume flow). Measurements of peak systolic velocity were also carried out. ABI examination is carried out for clinical evaluation of PAD. This study was conducted to look at the characteristics of $A B I$ and ultrasound results in the dorsalis pedis artery and posterior tibial arteries in diabetic foot ulcer at Cipto Mangungkusumo
National Hospital, Fatmawati National Hospital, and Tangerang Hospital.

\section{METHOD}

The study design was a cross-sectional prospective conducted on $11^{\text {th }}$ November $-15^{\text {th }}$ December 2014 at Cipto Mangungkusumo National Hospital, Fatmawati National Hospital, and Tangerang Hospital. The inclusion criteria used were diabetics and allow for ABI examination and ultrasonography. Patients who did not have a precise diagnosis and had undergone a major amputation of the leg examined were excluded from the study. Data was taken from the Division of Vascular Surgery and Endovascular Cipto Mangungkusumo National Hospital, Fatmawati National Hospital, and Tangerang Hospital. Data was calculated and processed to determine the relationship between $A B I$ and doppler ultrasound values.

\section{RESULTS}

In this study found more female patients ( 32 people; $60 \%$ ) than men ( 21 people; $40 \%$ ). The most common diabetes foot events were in the 50-54 year age group. Most patients were treated with leukocytosis (40 people; 75.5\%), irregular blood sugar control (38 people; $71.7 \%$ ), and hypoalbuminemia (52 people; $98.1 \%$ ). There was a history of not smoking in 37 patients $(69.8 \%)$. Most non-hypertensive samples were found in 41 patients $(77.3 \%)$, and no dyslipidemia was found in 42 patients $(79.2 \%)$. Of the entire study sample, none had renal insufficiency $(100 \%)$ (Table 1$)$.

The mean PSV of the dorsalis pedis artery was $41.57 \mathrm{~cm} / \mathrm{sec}$, while the median was 37.6 $\mathrm{cm} / \mathrm{sec}$, with the lowest value of $5.50 \mathrm{~cm} / \mathrm{sec}$ and the highest $99.5 \mathrm{~cm} / \mathrm{sec}$. The mean VF of the dorsalis artery was $27.27 \mathrm{~mL} / \mathrm{min}$, while the median was $17.64 \mathrm{~mL} / \mathrm{min}$, with the lowest value of $1.00 \mathrm{~mL} / \mathrm{min}$ and the highest $87.52 \mathrm{~mL} / \mathrm{min}$. The mean posterior tibial artery PSV was $45.18 \mathrm{~cm} / \mathrm{sec}$, while the median is $38.87 \mathrm{~cm} / \mathrm{sec}$, with the lowest value of 10.07 $\mathrm{cm} / \mathrm{sec}$ and the highest $90.59 \mathrm{~cm} / \mathrm{sec}$. The mean posterior tibial artery VF was $27.31 \mathrm{~mL} / \mathrm{min}$, while the median was $19.20 \mathrm{~mL} / \mathrm{min}$, with the lowest value of $1.00 \mathrm{~mL} / \mathrm{min}$ and the highest of $78.94 \mathrm{~mL} / \mathrm{min}$. Spectral image also obtained results of triphasic samples of 5 samples (9\%), biphasic as many as 25 samples $(47 \%)$, and monophasic as many as 23 samples $(44 \%)$. The mean ABI was 0.93 , while the median was 0.91 , with the lowest value 0.64 , and the highest 1.50. Normal ABI values were 26 samples (49\%) and 27 abnormal samples (51\%) (Table 2).

Abnormal ABI showed an abnormal spectral picture in 24 samples (45\%). Whereas in ABI, that was not normal with a typical spectral picture, only two samples (5\%). In normal ABI, there were 11 typical spectral images (22\%) and 15 abnormal spectral images (28\%) (Table 3 ).

The normality test with the KolmogorovSmirnov test was performed; all variables had a $\mathrm{p}$ value $<0.05$, so it concluded that the data was not normally distributed. Then the data was transformed, but the data still had an abnormal distribution. Based on this test, a non-parametric correlation analysis test was performed, namely the Spearman correlation test. 
Table 1. Distribution of characteristics of research subjects.

\begin{tabular}{|c|c|c|}
\hline Variable & $\begin{array}{c}\text { Total } \\
(n=53)\end{array}$ & $\begin{array}{c}\text { Percentage } \\
(\%)\end{array}$ \\
\hline \multicolumn{3}{|l|}{ Gender } \\
\hline Male & 21 & 40 \\
\hline Female & 32 & 60 \\
\hline \multicolumn{3}{|l|}{ Age (years) } \\
\hline $30-34$ & 1 & 1,9 \\
\hline $35-39$ & 0 & 0 \\
\hline $40-44$ & 3 & 5,7 \\
\hline $45-49$ & 8 & 15,1 \\
\hline $50-54$ & 12 & 22,6 \\
\hline $55-59$ & 11 & 20,8 \\
\hline $60-64$ & 10 & 18,9 \\
\hline $65-69$ & 3 & 5,6 \\
\hline $70-74$ & 4 & 7,5 \\
\hline $75-79$ & 1 & 1,9 \\
\hline \multicolumn{3}{|l|}{ Leukocytosis } \\
\hline Yes & 40 & 75,5 \\
\hline No & 13 & 24,5 \\
\hline \multicolumn{3}{|l|}{ Blood sugar } \\
\hline Controlled & 15 & 28,3 \\
\hline Uncontrolled & 38 & 71,7 \\
\hline \multicolumn{3}{|c|}{ Hypoalbuminemia } \\
\hline Yes & 52 & 98,1 \\
\hline No & 1 & 1,9 \\
\hline \multicolumn{3}{|l|}{ Smoking history } \\
\hline Yes & 16 & 30,2 \\
\hline No & 37 & 69,8 \\
\hline \multicolumn{3}{|l|}{ Hypertension } \\
\hline Yes & 12 & 22,7 \\
\hline No & 41 & 77,3 \\
\hline \multicolumn{3}{|l|}{ Dyslipidemia } \\
\hline Yes & 11 & 20,8 \\
\hline No & 42 & 79,2 \\
\hline \multicolumn{3}{|l|}{ Renal } \\
\hline insufficiency & 0 & 0 \\
\hline Yes & 53 & 100 \\
\hline No & & \\
\hline
\end{tabular}

From the Spearman non-parametric correlation analysis test results obtained significant results on the correlation between $A B I$ and posterior tibial artery VF $(p=0.021)$. In contrast, insignificant results were obtained on the correlation between PSV dorsalis pedis artery with ABI $(p=0.561)$, as well as on insignificant correlation between $\mathrm{VF}$ of dorsalis pedis artery with ABI $(p=0.143)$, as well as an insignificant correlation of posterior tibial artery PSV with ABI $(p=0.231)$ (table 5).

The table shows that Spearman's nonparametric correlation analysis test results obtained significant results on the correlation between $A B I$ with a spectral picture $(p=0,000)$ in diabetic feet (table 6$)$.

\section{DISCUSSION}

This study included 55 samples that met the inclusion criteria, 27 people from Cipto Mangunkusumo National Hospital, 22 people from Fatmawati National Hospital, and four people from Tangerang Hospital. In this study, it was seen that there were more female diabetic foot patients (32 people) than men (21 people). This was consistent with the recording of diabetic foot cases in 2013 at Cipto Mangunkusumo National Hospital, which showed that female patients were 1.5 times more than male patients. However, these data are inconsistent with several other epidemiological studies of diabetic foot ulcers. In the United States, more men than women, namely men 6.5/1000, whereas in women 6.1/1000, while in Romania (in 2008), Sydney (in 2011), and Egypt (in 2012), which shows that the highest incidence of diabetes is in men, with a ratio of men and women was $2: 1$.

The most common diabetes foot incidence was in the 55-54 year age group. The recording of diabetic foot cases at Cipto Mangunkusumo National Hospital showed the same dominance and age range. However, other research by Zaine et al., and Nwabudike et al., showed that the highest incidence of diabetes foot was in the $6^{\text {th }}$ decade. The age range of diabetes foot events in Indonesia was younger than similar epidemiological studies abroad. This is estimated to be caused by the level of public awareness of DM disease, which is still low, the level of education is still low, and the socioeconomics level is still low. DM patients are largely not treated regularly so that complications of DM itself, such as

Table 2. Distribution of ultrasound data of the dorsalis pedis artery, posterior tibial artery, and $A B I$ in the diabetic foot.

\begin{tabular}{lc}
\hline \multicolumn{1}{c}{ Variable } & $\begin{array}{c}\text { Diabetic foot ulcer } \\
(\mathrm{n}=53)\end{array}$ \\
\hline PSV of dorsalis pedis artery (cm/second) & \\
Mean (SD) & $41,57(2,24)$ \\
Median (range) & $37,6(5,50-99,5)$ \\
VF of dorsalis pedis artery (mL/minute) & $27,27(2,82)$ \\
$\quad$ Mean (SD) & $17,64(1,00-87,52)$ \\
Median (range) & $45,18(2,37)$ \\
PSV of tibialis posterior artery (cm/second) & $38,87(10,70-90,59)$ \\
$\quad$ Mean (SD) & $27,31(2,41)$ \\
Median (range) & $19,20(1,00-78,94)$ \\
VF of tibialis posterior artery (mL/minute) & \\
Mean (SD) & $5(9 \%)$ \\
Median (range) & $25(47 \%)$ \\
Spectral & $23(44 \%)$ \\
Triphasic & \\
Biphasic & $0,93(0,14)$ \\
Monophasic & \\
Ankle-brachial index & \\
Mean (SD) & \\
Median (range) & $26(49 \%)$ \\
Ankle-brachial index & $27(51 \%)$ \\
$\quad$ Normal & \\
Abnormal &
\end{tabular}


diabetic foot ulcers, occur faster than they should if blood sugar levels are always well controlled., ${ }^{1,3}$

Table 3. Distribution of spectral data on ultrasound of the dorsalis pedis artery/posterior tibial artery against $A B I$ in diabetic foot.

\begin{tabular}{ccc}
\hline Variable & $\begin{array}{c}\text { ABI } \\
\text { Normal }\end{array}$ & $\begin{array}{c}\text { ABI } \\
\text { Abnormal }\end{array}$ \\
\hline Spectral wave & & \\
Normal & $11(22 \%)$ & $2(5 \%)$ \\
Abnormal & $15(28 \%)$ & $24(45 \%)$ \\
\hline
\end{tabular}

Table 4. Normality test data on ultrasound of dorsalis pedis artery, posterior tibial artery, and

\begin{tabular}{|c|c|}
\hline Variable & $\begin{array}{l}\text { Normality test* } \\
\mathrm{p}\end{array}$ \\
\hline PSV of dorsalis pedis artery & 0,000 \\
\hline VF of dorsalis pedis artery & 0,000 \\
\hline $\begin{array}{l}\text { PSV of tibialis posterior } \\
\text { artery }\end{array}$ & 0,000 \\
\hline $\begin{array}{l}\text { VF of tibialis posterior } \\
\text { artery }\end{array}$ & 0,000 \\
\hline Ankle-brachial index & 0,000 \\
\hline
\end{tabular}

${ }^{*}$ Kolmogorov-Smirnov test comorbidity in diabetic foot ulcer patients in a row were smoking $51.25 \%$, hypertension $43.75 \%$ (higher than the study of the authors), and dyslipidemia $32.5 \%$ (higher than author research). In Indonesia, there are very few female smokers. In Indonesia, explained by the researcher of the Demographic Institute of the Faculty of Economics, Universitas Indonesia Abdillah Hasan, in 2007, the number of female smokers was 4.8 million out of the total smokers of 65.2 million $(7.36 \%)$. In this study most of the samples were women, so that it does not match the figures presented by Rizk et al. On the risk factors for hypertension, in contrast to Rizk et al., Supartondo et al., explained the prevalence of DM patients with hypertension by $39.9 \%$. The lower incidence of hypertension and dyslipidemia is estimated to be related to differences in living habits and diets of the study population of the authors who are in Indonesia with the research population Rizk et al., in Egypt. ${ }^{5}$

In this study also showed the distribution of ultrasound data of the dorsalis pedis artery, posterior tibial arteries, and ABI in diabetic feet. The ultrasound components in this study were PSV and VF of each dorsalis pedis artery, posterior tibial artery, and its spectral features. The mean PSV of the dorsalis pedis artery was $41.57 \mathrm{~cm} / \mathrm{sec}$, while the median was 37.6

Table 5. Correlation of ultrasound of the dorsalis pedis artery, and posterior tibial artery with diabetic foot

\begin{tabular}{|c|c|c|c|c|}
\hline \multirow[b]{2}{*}{ Variable } & \multicolumn{4}{|c|}{ Correlation test $^{*}$} \\
\hline & $\begin{array}{c}\text { PSV of dorsalis pedis } \\
\text { artery } \\
(n=53)\end{array}$ & $\begin{array}{c}\text { VF of dorsalis pedis } \\
\text { artery } \\
(n=53)\end{array}$ & $\begin{array}{c}\text { PSV of tibialis posterior } \\
\text { artery } \\
(n=53)\end{array}$ & $\begin{array}{c}\text { VF of tibialis posterior } \\
\text { artery } \\
(n=53)\end{array}$ \\
\hline \multicolumn{5}{|c|}{ Ankle brachial index } \\
\hline $\mathrm{p}$ & 0,561 & 0,143 & 0,231 & 0,021 \\
\hline$r$ & 0,082 & 0,204 & 0,167 & 0,317 \\
\hline
\end{tabular}

*Spearman test

Table 6. Correlation test data on the spectral picture of ultrasound on ABI diabetic foot.

\begin{tabular}{cc}
\hline Variable & Correlation* \\
\cline { 2 - 2 } & $\begin{array}{c}A B I \\
(n=53)\end{array}$ \\
\hline Spectral & 0,000 \\
$p$ & 0,581 \\
$r$ &
\end{tabular}

Most patients entered the hospital with a history of irregular blood sugar control (38 people; $71.7 \%)$, leukocytosis (40 people; $75.5 \%)$, and hypoalbuminemia (52 people; $98.1 \%$ ). In a study in India by Viswanathan et al., in 2005 , the rate of diabetic foot infection was around $7.6 \%(n=100)$. This is different from this study, which was the infection rate at $76.4 \%(n=55)$. In developing countries such as Indonesia, infection is still a scourge for diabetic foot disease, and this is one of the predictors of awareness of low DM with a high incidence of uncontrolled blood sugar levels (71.7\%). New DM patients come for treatment when they have severe DM complications such as infected diabetic foot ulcers. In this condition, the patient's systemic condition was not good, so the incidence of hypoalbuminemia was also quite high $(98.1 \%)$.

There were comorbidities such as smoking (16 people; $30.1 \%$ ), hypertension (12 people; $22.6 \%$ ), and dyslipidemia (11 people; $20.7 \%$ ), while risk factors for renal insufficiency were not found. Research by Rizk et al., showed the incidence of $\mathrm{cm} / \mathrm{sec}$, with the lowest value of $5.50 \mathrm{~cm} / \mathrm{sec}$ and the highest $99.5 \mathrm{~cm} / \mathrm{sec}$. The mean VF of the dorsalis artery was $27.27 \mathrm{~mL} / \mathrm{min}$, while the median was $17.64 \mathrm{~mL} / \mathrm{min}$, with the lowest value of $1.00 \mathrm{~mL} / \mathrm{min}$ and the highest of $78.94 \mathrm{~mL} / \mathrm{min}$. The mean posterior tibial artery PSV was $45.18 \mathrm{~cm} / \mathrm{sec}$, while the median was $38.87 \mathrm{~cm} / \mathrm{sec}$, with the lowest value of 10.07 $\mathrm{cm} / \mathrm{sec}$ and the highest $90.59 \mathrm{~cm} / \mathrm{sec}$. The mean posterior tibial artery VF was $27.31 \mathrm{~mL} / \mathrm{min}$, while the median was $19.20 \mathrm{~mL} / \mathrm{min}$, with the lowest value of $1.00 \mathrm{~mL} / \mathrm{min}$ and the highest of $78.94 \mathrm{~mL} / \mathrm{min}$. Spectral images also obtained results of triphasic samples of 5 samples ( $9 \%)$, biphasic as many as 25 samples $(47 \%)$, and monophasic as many as 23 samples (44\%). Earlier in July 2014, a study by Vendry at Cipto Mangunkusumo National Hospital found the mean dorsalis pedis artery VF in the diabetic foot was $12.02 \mathrm{~mL} / \mathrm{min}$, and the posterior tibial artery VF mean was $15.09 \mathrm{~mL} / \mathrm{min}^{7}$

This study also showed that the mean ABI was 0.93 , while the median was 0.91 , with the lowest value of 0.64 , and the highest was 1.50 . Previously, 2010, Patrianef's research at Cipto Mangunkusumo National Hospital found that the average ABI value of diabetic ulcer patients at the time of examination was 0.898 . A normal ABI score of 26 samples (49\%) and 27 abnormal samples (51\%) was obtained, which showed that the ischemic factor in the sample was slightly more dominant. In contrast to studies in the United States, the number of diabetic ulcers due to neuropathy was $28.5 \%$, and due to vascular disease, it reached $9.5 \%$. 
After all the ultrasound data of the dorsalis pedis artery, the posterior tibial arteries, and $A B I$ in the diabetic foot had been obtained, a data normality test was performed to determine whether the data were normally distributed or not. This test was important to determine the statistical analysis used to conduct an ultrasound correlation test of the dorsalis pedis artery, and the posterior tibial artery with $A B I$ in the diabetic foot. Data distribution was said to be normal if the amount of data above and below the mean is the same, or in the calculation of normality tests using the Kolmogorov-Smirnov test $p$ values $>0.05$ are obtained.

In this study, an abnormal ABI showed an abnormal spectral picture in 24 samples (45\%). Whereas in ABI, that was not normal with a normal spectral picture, only two samples (5\%). In normal ABI, a normal spectral picture of 11 samples (22\%) was obtained. This is consistent with the theory, which says that abnormal ABI describes an abnormal process in the intima tunica, causing changes in the spectral flow to be abnormal. In this study, there was also a discrepancy with the theory, namely a normal ABI picture on an abnormal spectral picture in 15 samples $(28 \%)$. Several factors affect changes in the spectral picture of triphasic, including body heat, where body heat can cause vasodilation and decrease resistance. Another factor is the technical examination; in this case, the placement or position of the ultrasound probe. ${ }^{8}$

This study also showed that ultrasound data of the dorsalis pedis artery, posterior tibial arteries, and $A B I$ in diabetic foot were not normally distributed, with $p$ values $<0.05$, even after data transformation was performed. Because the data distribution was not normal, then the correlation test used for the dorsalis pedis artery ultrasound, and the posterior tibial artery with ABI was Spearman non-parametric correlation test.

In this study also shows that all correlation test results of each independent variable and dependent variable had a value of $p>0.05$, except for one, so it was concluded that there was no correlation between PSV of the dorsalis pedis artery with ABI, there was no correlation between VF of the dorsalis pedis artery with $\mathrm{ABI}$, there was no correlation between the posterior tibial artery PSV and ABI, and there was a correlation between the posterior tibial artery VF and ABI. In India, a study by Premalatha $G$ et al. revealed that there was no significant correlation between $\mathrm{ABI}$ and Doppler ultrasound findings from 100 of its study samples.

Spearman's non-parametric correlation analysis test results obtained significant results on the correlation between $A B I$ and Spectral Images $(p=0,000)$ in diabetic feet. Ultrasound examination shows the anatomy of the blood vessels and blood flow profile by looking for the diameter, the presence or absence of atherosclerosis, blood flow waveforms, PSV, and VF of the blood vessels. Good ultrasound results can be displayed in the form of illustrations so that clinicians can see the location of existing vascular abnormalities, and endovascular interventions can only be planned based on the results of the ultrasound examination. Ultrasound examination has a sensitivity of $84 \%$ and a specificity of $93 \%$. $^{8}$

This research has a weakness: not doing comorbid analysis of research samples and grouping more specific etiologies, to screen for possible medical conditions that affect $A B I$ or doppler ultrasound results.

\section{CONCLUSION}

There was a significant correlation between the posterior tibial artery VF with ABI and the Doppler ultrasound spectral picture with $A B I$.

\section{CONFLICT OF INTEREST}

The author states the original work, and there is no conflict of interest in doing this research.

\section{ORCID ID OF AUTHORS}

\section{Dedy Pratama}

https://orcid.org/0000-0003-2043-3084

Mulawardi Mulawardi

https://orcid.org/0000-0002-9482-0012

Patrianef Darwis

https://orcid.org/0000-0002-4982-9034

\section{REFERENCES}

1. International Working Group on The Diabetic foot. In: International concensus on the diabetic foot. International Working Group on the Diabetic Foot, The Netherlands, 1999, pp 20-96.

2. Reiber GE, Boyko E, Smith DG. Lower extremity ulcers and amputations in individuals with diabetes. In: Harris MI (ed) Diabetes in America, $2^{\text {nd }}$ edition, National Institute of Health Publication No 95-1468. National Institute of Health, Bethesda, 1995,pp 409-427.

3. Boulton AJ. The diabetic foot: from art to science. The $18^{\text {th }}$ Camillo Golgi lecture. Diabetologia 2004; 47:1343-1353

4. Jusi Jang. Dasar Dasar IImu Bedah Vaskuler, edisi 4. Balai Penerbit FKUI: 2008

5. LA, Moore C, Schuberth JM, Wukick DK, Andersen C, Vanore JV, Diabetic foot disorders: a clinical practice guideline. J Foot Ankle Surg 2006;45(5):S2-66.

6. Landim MBP, Filho AC, Chagas ACP, Asymmetric dimethylarginine (ADMA) and endothelial dysfunction implication or atherogenesis. Clinics 2009;64(5):471-8.

7. Peretz A, Leotta DF, Sullivan JH, TrengaCA, Sands FN, Aulet MR, et al. Flow mediated dilatation of the brachial artery: an investigation of methods requiring further standardization. BMC Cardiovascular Disorder 2007;7:11

8. Roman MJ, Naqvi TZ, Gardin JM, Gerhard-Herman M, Jaff M, Mohler E. Clinical Application of Non-invasive Vascular Ultrasound in Cardiovascular Risk Stratification: A Report from the America Society of Echocardiography and the Society of Vascular Medicine and Biology. J Am Soc Echocardiogr 206;19:943-54 